\title{
Diagnostic and therapeutic management of sarcoma patients
}

\author{
Andreas Seeber
}

In this special issue of the Magazine of European Medical Oncology (MEMO) clinical experts are summarizing the most relevant topics regarding the management and treatment of sarcoma patients. Collectively, their message is clear-a centralized multidisciplinary tumour board is crucial to enhance outcome of sarcoma patients.

In her short review, Liegl-Atzwanger [1] provides insight into the highly complex field of sarcoma pathology that is characterized by high heterogeneity despite the low incidence of this disease. Specimen referral to a pathologist specialized in sarcomas is mandatory and of utmost importance to make an exact diagnosis which has important treatment-specific consequences.

Windhager et al. [2] present the central role of limbsparing surgery and highlight the importance of adequate R0 resection, which has an impact on the prognosis and survival of patients. Moreover, the authors describe high-level activity, such as sports, as a new potential scoring system to evaluate quality of life after limb-sparing surgery.

Next, Roeder [3] and Rothermundt [4] provide an in-depth review of perioperative radio- and chemotherapeutic strategies. Radiotherapy and chemotherapy are an integral part in multimodal treatment concepts for sarcoma patients. In a multidisciplinary tumour board, the use of those multimodal approaches should be discussed to increase, in addition to the local control rate, the relapse-free and overall survival. Especially, for patients with a highrisk profile neoadjuvant chemo- or radiotherapy, in-

\footnotetext{
A. Seeber, MD PhD $(\bowtie)$

Department of Hematology and Oncology, Comprehensive Cancer Center Innsbruck, Medical University of Innsbruck, Anichstraße 35, 6020 Innsbruck, Austria

Andreas.Seeber@tirol-kliniken.at
}

traoperative radiotherapy, as well as adjuvant radiotherapy and chemotherapy should be considered.

The palliative treatment of metastatic sarcoma patients is summarized by Grassi et al. [5]. They give insight into the standard of care as well as tailored treatment strategies using targeted and immune therapies and give an outlook on the development of new treatment strategies.

Finally, Thaler et al. [6] provide the state of the art of the management of patients with bone sarcomas. They present the critical and complex role of multimodal treatment concepts that include neoadjuvant chemotherapy and wide en bloc resection, followed by adjuvant treatment.

As a guest editor, I hope you will find these articles useful in giving you a short insight in the complex field of the management of sarcoma patients. The multimodal concepts are of utmost need to gain the best outcome for a patient diagnosed with this rare malignant disease. Thus, sarcoma patients should only be treated within sarcoma centers.

Sincerely,

Andreas Seeber MD PhD

Conflict of interest A. Seeber declares that he has no competing interests.

\section{References}

1. Liegl-AtzwangerB.Theroleofpathologyinsarcoma. memo. 2020. https://doi.org/10.1007/s12254-020-00574-4.

2. Windhager R, Hobusch GM. The role of surgery in soft tissue sarcoma: Can we improve outcome and function towards sporting activities?. memo. 2020. https://doi.org/10.1007/ s12254-020-00583-3.

3. Röder F. Radiotherapy in soft tissue sarcoma. memo. 2020. https://doi.org/10.1007/s12254-019-00562-3. 


\section{editorial}

4. Rothermundt C. Perioperative treatment of soft-tissue sarcoma. memo. 2020. https://doi.org/10.1007/s12254-01900555-2.

5. Grassi M, Spagnoletti A, Puccini A. Metastatic sarcoma: tailored strategies for a heterogeneous disease. memo. 2020. https://doi.org/10.1007/s12254-020-00598-w.

6. Thaler T, Khosravi I. Therapy management in bone sarcoma. memo. 2020. https://doi.org/10.1007/s12254-02000595-z.

Publisher's Note Springer Nature remains neutral with regard to jurisdictional claims in published maps and institutional affiliations.

- For latest news from international oncology congresses see: http://www.springermedizin.at/ memo-inoncology 